\title{
Reducing Tick Size One the Stock Exchange of Tunis
}

\author{
Halim Dabbou ${ }^{1}$ \\ ${ }^{1}$ High Institute of Management, Sousse, Tunisia \\ Correspondence: Abdel Aziz Elbahi, 4000 Sousse, Tunisia. Tel: 216-9824-6453. E-mail: hdabbou@yahoo.fr
}

Received: February 7, 2013 Accepted: May 10, 2013 Online Published: May 28, 2013

doi:10.5539/ijbm.v8n12p126 URL: http://dx.doi.org/10.5539/ijbm.v8n12p126

\begin{abstract}
Although before the 03-12-2007, the tick size in the Tunisian Stock Exchange was not high enough to constraint the spread, the authorities reduced it for certain stocks by adopting a single level of 10 millimes whatever the price level and trading frequency.

While referring to results of several researchers, we used to doubt that such a decision had ever been justified. Consequently, we have studied the impact of the reduction in tick size on return characteristics, liquidity and order revision strategy adopted by investors.

We found that the change of tick size has not affected the return characteristics of the stocks in the three months following the date of the change and this result is due to a certain conservatism of the investors who carry on submitting their orders mainly to the prices authorized before the change of the tick.

On the other hand, our results emphasize a deterioration of the liquidity for the stocks whose tick size was reduced and have a change in order strategy (for the stocks listed on the continuous) adopted by the investors who became more aggressive by revising frequently their orders.
\end{abstract}

Keywords: market efficiency, thinly traded market, tick sizes

\section{Introduction}

The frequent revisions of the rules adopted by several stock exchange authorities concerning the tick size show us on the one hand its great importance on the market quality and secondly the absence of a theoretical reference frame helping the authorities in their decision making.

In the absence of theoretical and empirical models allowing to identify the optimal tick size (if ever it exists) we will limit ourselves to specify the arguments in favor or against a given level of tick size.

As far as the arguments are concerned in favor of a large tick we will enumerate the following explanations:

- A high tick reinforces the priority rules on limit-orders book, then if the tick is very weak, certain investors can offer prices marginally better allowing them to gain the priority and discouraging the others to submit limit orders. Such a logic can only relate the order driven markets with a limitation of the hidden orders and a priority order based on the price and time, (Harris, 1994; Angel, 1997).

- A significant tick size reduces the negotiation costs. In the case of high tick the number of possible prices is reduced and thus the costs of negotiation will be reduced and operational efficiency will be improved consequently. (Grossman \& Miller, 1988; Bown, Laux, \& Schacter, 1991).

- $\quad$ The tick protects the dealers' limit orders from adverse selection (Harris, 1991).

- A tick reduction can cause a reduction of the spread which in its turn can reduce the exposure of the orders because the liquidity offer is less advantageous and riskier, thus the depth can decrease consequently.

- An important significant tick can improve the market liquidity. If the tick increases, the spread follows it and thus the revenue of market makers increases. In this case, several agents will engage in the activity of the market making inducing an improvement of the liquidity. Such an argument relates only to the price driven markets where a competition between the market makers is possible (case of the NASDAQ for example).

The principal argument in favor of a weak level is also the improvement of the liquidity! Currently the investors are interested in the profitability after transaction cost and that a weak tick is synonymous with a reduced cost. So the reduction of the tick size will encourage the investors to carry out frequent trading and thus attract new 
investors. This argument takes all its direction when the tick constrains the spread to take a value higher than its "normal value". In addition, a weak tick allows the release of an arbitrage process, even if the profit before transaction cost is weak, thus improving informational market efficiency.

It is obvious that a tick modification does not benefit to all the agents on the market. The majority of the researchers affirm indeed, that a weak level is beneficial to liquidity demanders since competition between liquidity suppliers reduces the spread and the transaction costs whereas this can be harmful to liquidity offerers whose margin will drop consequently reducing, their ability to offer liquidity.

The empirical studies treating the impact of the tick size on the market quality can be divided into four categories:

- The first category on the one hand integrates the studies which have been interested in the variation of market quality following a regulation change concerning the tick size. The majority of the results (Van Born, Van Born, \& Pruitt, 2000;, Chung \& Chuwonganant, 2004; Chung, Chuwonganant, \& McCormick, 2004) shows a tick reduction which generates a narrower spread and a less depth, on the other hand, rare are the studies which have evaluated the net effect of the tick change on the liquidity.

- The second category is interested in the changes of the spread for stocks which are transfered from a tick range to another on the markets where the tick is the function of the price levels.

- Third the work which studied the effect of a split operation on the quality of the market while being based on the fact that a split operation increases the tick size, it shows a widening of the spread after the split operation that encourages the brokers to promote the split operations (Copeland, 1979; Angel, 1997; Schultz, 2000).

- Finally, the fourth category has been focused on the study of the impact of the tick size on the correlation between the prices and the relative spread (Harris, 1994, 1996; Angel, 1997).

Before the 03-12-2007, the tick size on the Tunis Stock Exchange was variable according to the price level but without exceeding the 100 millimes as long as the prices are lower than thousand dinars. Although it is obvious that the levels practiced at that time did not constraint the spread, the authorities harmonized them by adopting a single level of 10 millimes whatever the price of the stock and its trading frequency.

While referring to several researchers, we extremely doubt that such a decision is justified. We will initially study the impact of the tick modification on the characteristics of the stocks and the liquidity.

Then we will test at the same time, the assumption of conservatism of the investors which stipulates that the investors will continue to pass their orders mainly with the prices authorized before the change of the tick. The validation of such an assumption would explain the absence of tick modification impact on the characteristics of the returns and also on the liquidity. Secondly time we will be interested in the behaviors of the investors making revision of orders (cancellation and modification) around the date of the lawful change.

Without paying any attention the differences of the characteristics of returns, trading volume and liquidity between the securities listed on continuous and those on fixing, so it is useful to distinguish between these two types of stocks for determining better the effect of the tick size modification.

Then, our second paragraph is devoted to a review of the literature treating the impacts of the tick size on the liquidity and on the characteristic of the stocks. Then we present our data in a third paragraph, methodology in a fourth paragraph and the results and interpretations at last.

\section{Review of the Literature}

\subsection{The Tick Size and Liquidity}

The first empirical studies, which have analyzed the relation between the tick size and the liquidity, were limited to study the spread and the depth whereas recent research has widened its analysis with other facets of the liquidity by using direct and indirect measurements, such as the trading volume, volatility, the activity of orders submission in addition to a liquidity index incorporating inter alia the spread and the depth.

As far as price driven markets as concerned the tick size is higher than the spread, the latter will equalize the tick and liquidity offers as being advantageous, especially for the small orders. In addition, the dealers will change their strategy of quotation thus impacting the depth of the order book. For example, if the market applies to the temporal priority, the suppliers of liquidity will make the tail to offer the liquidity thus increasing the depth.

But the tick can affect the depth even if the quoted spread is higher than the tick. If the tick, which represents the minimum cost of obtaining the priority of orders in the order book, is high, the probability of being preceded by the quote matchers will be weaker. Thus the depth would be positively related to the tick. 
(Harris, 1994) uses American data (NYSE and AMEX) to carry out a projection of the spread, depth and trading volume following one supposed as a change of tick size. He finds that a reduction of the tick can allow a significant reduction of the spread and an increase in trading volume but also a reduction in the size of the orders which does not indicate necessarily a fall of the depth.

By studying the reduction of the tick size from $1 / 8$ to $1 / 16$ on the NYSE, (Bollen \& Whaley, 1998) note a significant fall of the spread and find that the quoted spread weighted by trading volume decreases of more than $13 \%$ but that the depth falls of $38 \%$ after the change. By using an index of the market quality, they conclude a modest improvement of the market quality.

The authors find that the effect of the tick reduction is not homogeneous with the price range and from the size of the transactions and that in particular the stocks at weak price will benefit well from the reduction of the tick and thus deducing the existence of an optimal level of tick.

By analyzing the impact of the reduction of the tick size on the liquidity in the NYSE, (Goldstein \& Kavajecz, 2000) suggest that the determination of the tick must be done according to the levels of trading volume and price. The heavily traded stocks must be equipped with a weak tick whereas thinly traded ones must have a high tick.

(Ronen \& Weaver, 2001) study the impact of the reduction of the tick size on the AMEX on the liquidity, the volatility and the specialist profit. They find an improvement of the liquidity (confirmed by the fall of the spread with non- reduction of the depth), a reduction in the transaction costs (accompanied by a stability of the specialist profits) and finally, a reduction of volatility.

By studying the reduction of the thick size on Nasdaq, (Bessembinder, 1999) concludes the equilibrium spread depends on the level of tick even if this last does not constrain directly the width of the spread.

(Ascioglu, Comerton-Forde, \& McInish, 2010) try to determine the criteria which the authorities must use to fix the level of the tick. They conclude that the authorities must take account of the trading activity as well as price range to fix the level of the tick. The same conclusion is reached by (Aitkena \& Comerton-Forde, 2005) following a study of the reduction of the tick on the Australian market.

On a driven order market, the only source of liquidity comes from the limit orders. It is thus imperative that the tick is on a level which encourages the submission of limit orders and offers a protection against the free-riders. On the other hand, an elevated tick harms to the liquidity claimants seen the increase of transaction costs.

(Chung, Kim, \& Kitsabunnarat, 2005) study the impact of the tick on the quality of Kuala Lumpur market characterized by seven different ticks according to the price. They find that the imposition of a high tick for the stocks at high price is not without defect since their relative spread are broader than those of the other stocks whereas their depths are not better for as much. On the other hand, the authors observe that the clustering of quotations decreases with the tick, and affirm that the liquidity suppliers do not always offer important depths for the stocks with high tick. They conclude that high ticks for stocks at important prices can deteriorate the liquidity while reducing the cost of transaction (less clustering of quotations).

(Smith, Turnbull, \& White, 2006) have analyzed the impact of the reduction of the tick of January 29th 2001 on the Toronto Stock Exchange quality. They have found that the trader's choice of strategy related to the order priority is not affected by the tick reduction and that the frequency of the cancelled orders increased.

(Smith, Turnbull, \& White, 2006) have found that the reduction of the tick generates a reduction in the spread for the least liquid stocks, a fall depth of the market, an increase of the speed of orders execution and an improvement of the price continuity.

Contrary to former research, (Bourghelle \& Declerck, 2004) have not found any significant variation of the effective and quoted spread for the whole of the stocks following the revision of the tick size of January 1999 on Euronext of Paris. They deduce that the relation between the relative tick and the relative spread is increasing but convex.

For the depth and the orders submission, the results coincide with former research:

- The authors have shown that the investors use more hidden orders following the tick reduction and conversely less than hidden orders for the stocks whose tick has increased.

- The submission of the limit orders within the limits of the spread increased (decreased) following the reduction (increase) of the tick. Thus, the tick reduction is related to the reduction of quoted depth.

In addition the authors note, that institutional which is supposed being responsible of the big size orders, did not suffer from the tick change since they have found variation of the weighted average spread by the trading 
volume.

The authors have observed finally, a change in the behavior of the traders who protect themselves from the strategies of front-running. They have concluded that a tick change does not necessarily lead to a change of the execution costs but it influences the transparency level on the side of the liquidity offer. Normally a broad tick makes the strategies of front running expensive and encourages the investors to expose their orders, whereas a weak tick permit the investors to obtain the priority to carry out their orders with a weak price sacrifice.

(Harris, 1996) studied the relation between the orders exposure and the tick size on the Toronto and Paris stocks exchange. He found that the investors are more exposed in the cases of broad tick, short order validity and low price volatility confirming the fact that the dealers who submit limit orders try to control the option which they offer to the others.

The results had shown well that the tick had affected the order exposure, which meant that tick reduction had decreased the order exposures and possibly the liquidity.

In conclusion, we can say that the net effect of a tick revision on the execution cost and on the liquidity can depend on the market design. For example, the anticipated results of the Kadan model (2006) have been far from being waited in a market where there is no competition of market makers; the results as well as the explanations have differed between order driven market and dealer market.

(Kadan, 2006) derived a model permitting to clear up the relation between the number of market makers and the effect of a tick change. On the one hand he found that if their number were small, they would prefer a weak tick whereas the investors attitude were ambiguous but with a certain preference of high level. On the other hand, if their number was high, the market makers would prefer a high tick contrary to the investors.

In the same way, the existence of hidden orders on a given market is decisive in the determination of an "optimal" tick since in this case the liquidity suppliers can protect themselves while avoiding offering to the others free options. Lastly, the rules of orders priority can play a big role in this context.

\subsection{Tick Size and Return Characteristics}

The analysis of the impact of the tick size on the return characteristics did not much draw the attention of the researchers, but the intuition wants the tick to create a price clustering, thus causing a distortion compared to a normal distribution, especially for the return calculated on a short time interval. In the same way, this clustering can influence the trading volume and volatility.

(Onnela, Tôyli, \& Kaski, 2009) have studied the effect of a tick change on the returns by using two approaches one based on a simulation and the other on real data.

So in the first study, these latters generate time series of price with a normal distribution of the returns, then they discretize these series to simulate the existence of a not null tick size before reanalyzing their characteristics. Thus, any change obtained is supposed to reflect the effect of the tick on the return.

Simulations carried out have shown that the data made discrete (in conformity with the existence of the tick size) are not described any more by a normal distribution and that a better approximation can be obtained by using a more pointed distribution.

In the second study, they choose securities listed at the same time on the NYSE and Toronto Stock Exchange which do not use the same level of tick. The authors note that the investors frequently use "psychological" prices, with the result that the prices are not uniformly distributed on the grid of the possible prices. This clustering of the prices on the level of certain values can affect the manner with which the returns are distributed. Moreover, this phenomenon persists even after the reduction of the tick (decimalization on the US stock exchange) because the investors are touched by a form of conservatism. The authors find that the tick size and the ratio tick on price influence the frequency of the null returns and that the broad effective levels cause a distortion of the form of the return distribution because inter alia high frequency of the null returns.

Thus, the empirical results are not in agreement with the results of simulations because possibly of the conservatism of the investors who continued to trade with the same prices used before decimalization.

(Munnix, Schäfer, \& Guhr, 2010) show that a tick even weak influences significantly the structure of the return distribution. If a stock reveals important changes of price during a given period of time, its return distribution will have thicker tails.

In addition, decimalization can deform the calculation of the returns in particular for the stocks valued at low prices. In addition the authors show that the tick size induces errors on the calculation of the correlation 
coefficient due to a bad standardization of the return. This distortion depends on the impact of the decimalization which increases the returns calculated on short intervals thus contributing to the Epps effect which appears by the fall of the correlation coefficients as the returns have been calculated on decreasingly time intervals.

(Hameed \& Terry, 1998) find a clustering of the prices which is important for all the ranges of price but which increases with the rise in the tick size and decreases with the trading volume without influence the price volatility. (French \& Foster III, 2002) analyze the increase in volatility following a split operation before and after 1997, date of tick size reduction on the main American stocks exchanges. They find that except for the securities listed on the AMEX, the post-split variance increase was unaffected by the reduction in tick size.

\section{Data}

At the date of the change of the regulation concerning the tick size, only 18 out of 50 stocks saw their tick size reduced as shown at table 1 .

Table 1. Number of firms listed on the Tunisian stock exchange according to their prices on the 03-12-2007 date of tick size change

\begin{tabular}{lccccc}
\hline & Continuous & Fixing & Total & Tick before 03-12-2007 & Tick after 03-12-2007 \\
\hline Price $<20 \mathrm{~d}$ & 22 & 10 & 32 & $0.010 \mathrm{dinar}$ & \\
$20 \mathrm{~d} \leq$ price $<100 \mathrm{~d}$ & 9 & 8 & 17 & $0.020 \mathrm{dinar}$ & $0.010 \mathrm{dinar}$ \\
$100 \mathrm{~d} \leq$ Price $<1000 \mathrm{~d}$ & 0 & 1 & 1 & $0.100 \mathrm{dinar}$ & \\
Price $\geq 1000 \mathrm{~d}$ & 0 & 0 & 0 & 1 dinar & \\
Total & 31 & 19 & 50 & & \\
\hline
\end{tabular}

The data used are collected from BVMT databases. The study period covers six months and it is centered on the date of the 03-12-2007 corresponding to the day of regulation change concerning the size. We did not eliminate the week surrounding the date of the change not to lose precision whereas certain studies made it in order to avoid possible errors on the data (for example (Goldstein \& Kavajecz, 2000)).

A daily frequency has been used for all the analyzed variables. For the prices, the spreads and the depths, we chose the closing values.

On the level of methodology, we considered to be useful to establish a comparison with a control sample since at the end and at the beginning of the year, we can expect a particular behavior of the investors who are generally more active during this period compared to the remainder of the year. In fact, during December, certain investors have intervened on the market for tax reasons whereas the managers of funds have readjusted their portfolios for trade raisons. In addition, January has been characterized by a certain seasonal variation on some markets.

In the same way, and seen specificities of the quotation system, a distinction has been established between the stocks quoted on fixing as well as on continuous. In this direction, the control sample for the stocks listed on the continuous and affected by the tick reduction is made up only of stocks listed on the continuous and not having undergone a tick modification, the same way as for those listed on fixing.

To the date of the change, 33 stocks have belonged to continuous; those left have been listed in the fixing. During our study period, only one title whose tick has been modified has been transferred from fixing to continuous whereas for the control sample four stocks have passed from fixing to continuous at the 02-01-2008.

As an estimate of the returns and the spread, we use first the limit crossed in the case of trading halts then in the case of absence of quotation, we use the previous price on condition that the spread is positive. If not, we use price of the following day.

Lastly, for the securities listed on fixing, seldom, were some exchanged during the analysis period, which we could not calculate their skewness and kurtosis any more thus we have eliminated them from our samples.

\section{Methodology}

\subsection{Characteristics of the Returns}

For each stock we have calculated the return before and after change of tick size level, like their characteristics (average, variances, skewness and kurtosis) then we have estimated the absolute difference (average frontaverage after). 
We have also calculated the arithmetic means of the variable studied before and after 03-12-2007 for each of the four groups (fixing, control fixing, continuous and control continuous).

A unilateral Student test per pairs has been used initially to test the change of the average after this date. To isolate the effect of the tick change of a possible change of the market conditions during the same period, we have tested the average difference between the sample of the stocks touched by the tick reduction and the sample of corresponding control, through $\mathrm{Z}$ test. Lastly, we have carried out a test of Wilcoxon for two matched samples to confirm the found results.

In the second time we have resorted to a $\operatorname{GARCH}(1,1)$ model with a dummy variable in the equation of the variance to test if the conditional variance have been affected by the change of the tick. The estimate was carried out over period 02-01-2007/30-06-2008 by using daily returns calculated on the basis of adjusted closing price. The dummy variable has taken zero value for the days preceding the tick change date and the value one in the following days. The estimated model arises as follows:

$$
\begin{aligned}
& R t=\phi_{0}{ }^{+} \phi_{1} R t-1+\varepsilon t \\
& 2 \\
& h t=\alpha 0^{+} \alpha 1 \varepsilon t-1{ }^{+} \beta_{1} h_{t-1} \\
& \varepsilon t / \psi_{t-1} \rightarrow N\left(0,{ }_{h t}\right)
\end{aligned}
$$

Where $R_{t}$ is the current return of a given stock and $\varepsilon t$ an error term.

$h_{t}$ is current conditional volatility.

$\alpha_{0}>0$ and the coefficients $\varepsilon_{1}$ and $\beta_{1}$ are positive or null.

\subsection{Liquidity}

For each stock, we have calculated the liquidity over the periods before and after the change, as measured by the trading volume, the spread, the depth with the best offer, the depth with the best demand, the index of market quality (MQI) then we estimate the relative difference by the logarithm (average before/average afterwards).

Three measurements of the trading volume have been used: the number of transactions per day, the number of stocks traded and the trading volume in dinars (expressed in a thousand of dinars).

In addition, we have calculated two types of spread:

Quoted spread (expressed in dinars) $=$ closing bid price - closing ask price.

Relative spread (expressed in $\%)=2 *($ closing bid price-closing ask price)/(closing bid price + closing ask price) .

Whereas for the index of liquidity, we retained the measurement used by Bollen and Whaley (1998):

$\mathrm{MQI}=($ depth with the purchase + depth with the sale $) / 2 *$ relative spread

The use of the logarithm reduces the effect of the outliers values whereas the use of the ratio adjusts the differences in scale between the firms. For each sample, we have measured the cross sectional average and the standard deviation of the logarithms before resorting to a student test to see whether the average change is significantly equal to zero or not.

Calculations are carried out on each of the two samples and their control samples before testing the differences of them.

For the stocks listed on fixing, have regard with the sample size and the illiquidity of certain stocks, it was impossible to us to carry out calculations of the spread and depth.

\subsection{The Activity of the Investors}

For each stock we have entered the number of the sale and buying orders three months before and three months after the date of the change as well as the number of modified and cancelled orders to be able to calculate the revision frequency for each type of order. We have then applied the Student test for matched samples to the frequencies average before and after the date of the change for the four groups of stocks. As for the liquidity and the characteristics of the stocks, comparisons are carried out between the stocks which underwent changes and the stocks of control pertaining to the same group of quotation. 


\section{Results and Interpretations}

\subsection{Characteristics of the Returns}

For the stocks listed on the continuous and affected by the tick change, we noted a statistically significant increase in the standard deviation (with a risk of $10 \%$ ) during the post change period. But the analysis of the corresponding control sample shows us the same phenomenon, namely a significant growth of the standard deviation. Moreover, the Student test does not reject the equality of the increases for the two samples. We then conclude that increase is not caused by the tick change but rather by other common factors related to the market conditions (table 2).

Table 2. Summary of characteristics of each group studied before and after the change date (The probability of Student test, applied on each variable before and after the change date, are indicated)

\begin{tabular}{|c|c|c|c|c|c|c|c|c|}
\hline \multirow{3}{*}{ Return average } & \multicolumn{2}{|c|}{ Fixing } & \multicolumn{2}{|c|}{ Control fixing } & \multicolumn{2}{|c|}{ Continuous } & \multicolumn{2}{|c|}{ Control continuous } \\
\hline & & prob & & prob & & prob & & prob \\
\hline & 0.00164 & & 0.00045 & & 0.00049 & & -0.00014 & \\
\hline Return-before & 0.00199 & 0.31 & -0.00116 & 0.06 & 0.00034 & 0.40 & 0.00013 & 0.13 \\
\hline Return-post & 0.00127 & & 0.00211 & & 0.00064 & & -0.00041 & \\
\hline Difference & -0.00073 & & 0.00326 & & 0.00030 & & -0.00054 & \\
\hline Standard deviation & 0.01102 & & 0.01272 & & 0.01263 & & 0.01222 & \\
\hline Standard deviation- before & 0.00968 & 0.11 & 0.01166 & 0.39 & 0.01138 & 0.08 & 0.01143 & 0.08 \\
\hline Standard deviation-post & 0.01147 & & 0.01227 & & 0.01339 & & 0.01272 & \\
\hline Difference & 0.00180 & & 0.00061 & & 0.00201 & & 0.00129 & \\
\hline Skewness & -1.11264 & & 0.29929 & & 0.37620 & & 0.26166 & \\
\hline Skewness-before & -1.53999 & 0.16 & 0.22780 & 0.42 & 0.19072 & 0.15 & 0.16674 & 0.13 \\
\hline Skewness-post & 1.33227 & & 0.19079 & & 0.59759 & & 0.28880 & \\
\hline Difference & 2.87225 & & -0.03701 & & 0.40687 & & 0.12205 & \\
\hline kurtosis & 15.61273 & & 1.90168 & & 3.33359 & & 1.76831 & \\
\hline Kurtosis-before & 12.12175 & 0.42 & 1.58593 & 0.39 & 1.97088 & 0.09 & 1.25372 & 0.08 \\
\hline Kurtosis-post & 12.34761 & & 1.88123 & & 3.33309 & & 2.04583 & \\
\hline Difference & 0.22586 & & 0.29530 & & 1.36221 & & 0.79211 & \\
\hline
\end{tabular}

For the stocks listed on fixing, the increase in the standard deviation is not statistically significant as well as for the sample made up of the stocks whose tick was reduced for the control sample.

For the skewness coefficient, we did not detect statistically significant changes for the whole of the analyzed samples. On the level of the stocks listed on the continuous, the skewness average increases almost threefold without being statistically significant thus showing a great disparity between the stocks and on the level of the stocks quoted on fixing, the skewness average straightforwardly has changed sign. So we can affirm that the tick change does not have affected the returns skewness of the securities quoted on the Tunisian Stock Exchange.

For the kurtosis, we have found an increase of about $70 \%$, statistically significant at the risk of $10 \%$ during the period post-change for the stocks listed on the continuous one and touched by the tick modification. Having noticed the kurtosis of the control sample which has increased by $63 \%$, we conclude then the non relevance of the tick change on the kurtosis.

For the stocks quoted on fixing, no change of kurtosis has been noted for the whole of the stocks (affected or not by the tick change).

The results of GARCH $(1,1)$ model estimate show that the dummy variable is significant as far as $60 \%$ of the stocks are concerned and that besides some exceptions, it is positive. So we can easily note that the result does not depend on the tick modification. Thus, as for the standard deviation, conditional volatility exhibits a change after the $03-12-2007$ which is not due to the tick modification. It could be either charged to the other regulatory 
modifications noted on this same date or with the year-end and January effects.

Globally, everything will indicate that the tick change hasn't affected the characteristics of stock returns. A plausible explanation of such a result discussed among others by (Onnela, Tôyli, \& Kaski, 2009) lies in the conservatism of the investors who will continue to operate on the market to place the orders mainly with the old authorized prices. To validate this possible explanation, we estimate for each stock the percentage of transactions carried out with the new possible prices on the number of transactions carried out.

Independently of the "psychological prices" preferred by the investors, this percentage should normally be equal to $50 \%$, but it accounts for only $13 \%$ for the stocks listed on continuous, $17 \%$ for those listed on fixing did not reach the $50 \%$ for any stock ; for instance, the stocks listed on continuous has a maximum value of $32 \%$ for the Simpar stock. Therefore a Student test confirms this conservatism at the risk of $1 \%$.

Thus we can conclude, that the investors have continued to use mainly the prices to which they were accustomed to place their orders, at least three months after the change.

\subsection{Liquidity}

\subsubsection{Trading Volume}

By analyzing the group of the stocks listed on the continuous and whose tick size was reduced, we noted an important increase in the volume of capital traded $(+90 \%)$ but which is statistically non significant. In the same way, as table 3 shows, the number of shares traded knew a very important increase after the 03-12-2007 for the whole of the sample listed on the continuous $(+93 \%)$ but this increase is not statistically significant. In fact, for certain stocks, belonging to the sample, the trading volume (measured as well by share number as by dinars) more than doubled whereas it dropped for others.

By using the transaction number as measure of trading volume, we found an increase statistically significant (risk of $1 \%$ ) of the trading volume after the tick size change. Such results can be explained by a behavioral change of the investors who would have reduced on average the size of their orders.

On the other hand, the observation of table 4 summarizing the evolution of the trading volume for the group of stocks listed on the continuous and whose share price is lower than 10 dinars (thus non affected by the tick size reduction), indicates that as well the transaction number, the share number and the volume of capital traded increased to a significant degree lasting the second period.

The comparison of the results of the two groups proves, in a certain manner, a relative reduction in the trading volume for the stocks whose tick size decreased.

Table 3. Evolution of liquidity before and after 03-12-2007 for the stocks listed on continuous (The $\mathrm{z}$ test has applied on the logarithm of the variable before on the variable after)

\begin{tabular}{lcccccccc}
\hline $\begin{array}{l}\text { Liquidity: } \\
\text { Continuous Group }\end{array}$ & $\begin{array}{c}\text { Number of } \\
\text { transactions }\end{array}$ & $\begin{array}{c}\text { Number } \\
\text { of stocks }\end{array}$ & $\begin{array}{c}\text { Depth } \\
\text { Ask }\end{array}$ & $\begin{array}{c}\text { Depth } \\
\text { Bid }\end{array}$ & Depth & Spread & Capital & MQI \\
\hline Mean before & 11.3510 & 3775.9 & 225.88 & 144.3545 & 370.2416 & 0.0139 & 142659 & 32.4341 \\
Mean after & 18.0370 & 7301.1 & 218.50 & 155.9370 & 374.4463 & 0.0124 & 271779 & 36.9160 \\
Difference & 6.6861 & 3525.2 & -7.377 & 11.5825 & 4.2047 & -0.0016 & 129120 & 4.4820 \\
z test probability & 0.0012 & 0.3180 & 0.4169 & 0.2771 & 0.3734 & 0.9775 & 0.2575 & 0.1934 \\
\hline
\end{tabular}

Table 4. Evolution of liquidity before and after 03-12-2007 for the control group (The $\mathrm{z}$ test has applied on the logarithm of the variable before on the variable after)

\begin{tabular}{lcccccccc}
\hline $\begin{array}{l}\text { Liquidity: Control } \\
\text { Group }\end{array}$ & $\begin{array}{c}\text { number of } \\
\text { transactions }\end{array}$ & $\begin{array}{c}\text { Number } \\
\text { of stocks }\end{array}$ & capital & $\begin{array}{c}\text { Depth } \\
\text { Bid }\end{array}$ & $\begin{array}{c}\text { Depth } \\
\text { Ask }\end{array}$ & Depth & Spread & MQI \\
\hline Mean before & 17.39 & 7630 & 49753 & 617 & 650 & 1268 & 0.015 & 84.70 \\
Mean after & 20.13 & 15386 & 71962 & 859 & 682 & 1542 & 0.013 & 132.38 \\
Difference & 2.73 & 7756 & 22209 & 241 & 31 & 273 & -0.002 & 47.68 \\
The z test probability & 0.008 & 0.013 & 0.009 & 0.002 & 0.126 & 0.008 & 0.951 & 0.068 \\
\hline
\end{tabular}




\subsubsection{Spread}

By analyzing the evolution of the quoted spread and the relative spread, we have found a fall lasting the posttick change period of the stocks listed on continuous and whose tick size fell. On average, the spread dropped by 0,036 dinar (but in a way statistically non significant) and the relative spread by $11.24 \%$ compared to its initial level (statistically significant with the risk of 5\%). However, by analyzing the spread of the control sample, we note the same evolution recorded by the first sample that is a non significant fall of the quoted spread and a statistically significant fall of the relative spread (but at the risk of $10 \%$ ). Moreover, no significant difference is detected between the falls of the spreads for the two samples what does not enable us to conclude that the spread fall is due to the tick size reduction.

\subsubsection{Depth}

For the depth, we did not detect any significant variation either with the best offer or with the best demand. Moreover, for the depth with the best demand we have found a non significant reduction whereas the depth with the best offer recorded a weak non significant increase. The same result was found for the total depth.

On the other hand, for the control sample made up of the firms listed on the continuous, we find an increase of $2156 \%$, statistically significant (at the risk of $1 \%$ ) of the depth during the post-change period which is mainly due to an increase of the depth on the best offer.

So we conclude that the depth of our basic sample was affected by the regulation change as that it did not increase in the same way as the control sample. Therefore, the tick reduction reduced the depth of the stocks concerned.

\subsubsection{Liquidity Index}

By using an index of liquidity we did not find a significant improvement of the liquidity for our basic sample whereas on the contrary at the risk of $10 \%$, the liquidity improved during the second period for the control sample.

We can thus conclude that the tick reduction did not improve the liquidity and that it possibly destroyed it. But the assumption of equality of the variations of the liquidity index of the two samples could not be rejected calling into question such a possibility.

\subsection{Investors Activity: Submission and Revision of the Orders}

The sellers submitted and revised more their orders that the purchasers for the stocks quoted before and after the date of the 03-12-2007, which can be explained partly by the bullish tendency of the Tunisian market during this period.

For the securities quoted on the continuous and having undergone a tick reduction, the sale orders increased of more than $52 \%$ during the three months following the change date compared to the three months which it preceding whereas during the same period the sale orders relative to the others stocks listed on the continuous increased only by $6.4 \%$. In the same way, the number of revised orders (cancelled or modified) increased by $57 \%$ for the studied sample whereas it increased only by $4.8 \%$ for the control sample (Table 5 ).

At the risk of $5 \%$, we cannot reject the assumptions of increase in the numbers of orders submitted, cancelled and modified, which is not the case for the control sample.

For the stocks affected by the tick modification and listed on fixing, although the average percentage of orders revision passed from $12.64 \%$ to $17.45 \%$, the statistical tests do not confirm the increase in the revised orders. In the same way, the number of submitted orders increased by $78.41 \%$ for the whole sample but without being statistically significant whereas for the control sample, made up of the stocks listed on fixing and not having undergone tick modification, the number of orders increased (statistically significant at the risk of $10 \%$ ) of $34.39 \%$ and the revision of the orders increased by $18.55 \%$ (statistically non significant).

The results concerning the buying orders did not differ much from those of the sale orders. Indeed, we have found that for the stocks listed on the continuous, the tick reduction generated a significant growth of $33.94 \%$ of the submitted orders (with the risk of 5\%) accompanied by an increase of $35.26 \%$ of the revised orders (significant at the risk of 10\%). For the control sample, the increases in the submitted and revised orders are not significant and are about $5.4 \%$ and $1 \%$ respectively.

As for the stocks listed on fixing, the increase in the orders submission is only of $17 \%$ compared with $28 \%$ for the control sample and we cannot statistically reject the assumption as being null. In the same way, the orders revision rather dropped by $14.69 \%$ without being significant at the time when it increased by $23.60 \%$ for the 
control sample (in a non significant way).

Table 5. The frequency of order modification

\begin{tabular}{lcccc}
\hline \multirow{2}{*}{} & \multicolumn{2}{c}{ The frequency of } & \multicolumn{2}{c}{ order modification } \\
\cline { 2 - 5 } & \multicolumn{2}{c}{ Bid order } & \multicolumn{2}{c}{ Ask order } \\
\cline { 2 - 5 } & before & after & before & after \\
\hline Continuous & 0.1334 & 0.1320 & 0.1465 & 0.1542 \\
Control continuous & 0.1194 & 0.1133 & 0.1265 & 0.1225 \\
Fixing & 0.1844 & 0.1110 & 0.1265 & 0.1746 \\
Control fixing & 0.1282 & 0.1462 & 0.1473 & 0.1449 \\
\hline
\end{tabular}

\section{Conclusion}

The reduction of the tick size decided by the Tunisian authorities the 03-12-2007 has challenged us and has incited us to study his impact on the characteristics of concerned stocks returns, on their liquidity and on the behavior of the investors as regards revision of the orders.

We have found that the tick change hasn't affected the characteristics of stock returns (standard deviation, skewness and kurtosis) in the three months which followed the date of the change; we have explained this result by a certain conservatism of the investors who continued to carry out the trading mainly with the prices to which they were accustomed.

Nevertheless, our results emphasize a deterioration of the liquidity for the stocks whose tick size was revised downward and a change in the order submission strategies (for the stocks listed on continuous) adopted by the investors who became more aggressive, frequently revising their orders.

\section{References}

Aitken, M., \& Comerton-Forde, C. (2005). Do Reductions in Tick Sizes Influence Liquidity? Accounting and Finance, 45, 171-184. http://dx.doi.org/10.1111/j.1467-629x.2004.00128.x

Angel, J. (1997). Tick Size, Share Prices, and Stock Splits. Journal of Finance, 52, 655-681. http://dx.doi.org/10.1111/j.1540-6261.1997.tb04817.x

Ascioglu, A., Comterton-Forde, C., \& McInish, T. (2010). An Examination of Minimum Tick Sizes on the Tokyo Stock Exchange. Japan and the World Economy, 22, 40-84. http://dx.doi.org/10.1016/j.japwor.2009.06.006

Bessembinder, H. (1999). Trade Execution Costs on NASDAQ and the NYSE: A Post-Reform Comparison. Journal of Financial and Quantitative Analysis, 34(3), 387-407. http://dx.doi.org/10.2307/2676265

Bollen, N., \& Whaley, R. (1998). Are 'Teenies' Better? Journal of Portfolio Management, 25, 10-24. http://dx.doi.org/10.3905/jpm.1998.10

Bourghelle, D., \& Declerck, F. (2004). Why Markets Should not Necessarily Reduce the Tick Size. Journal of Banking \& Finance, 28(2), 373-398. http://dx.doi.org/10.1016/S0378-4266(03)00136-5

Brown, S., Laux, P., \& Schacter, B. (1991). On the Existence of Optimal Tick Size. Review of Futures Markets, 10, $50-72$.

Chung, K. H., \& Chuwonganant, C. (2004). Tick Size, Order Handling Rules, And Trading Costs. Financial Management, 33(1), 47-62.

Chung, K. H., Kim, K. A., \& Kitsabunnarat, P. (2005). Liquidity and Quote Clustering in a Market with Multiple Tick Sizes. Journal of Financial Research, 28, 177-195. http://dx.doi.org/10.1111/j.1475-6803.2005.00120.x

Chung, K., Chuwonganant, C., \& McCormick, T. (2004). Order Preferencing and Market Quality on NASDAQ Before and After Decimalization. Journal of Financial Economics, 71, 581-612. http://dx.doi.org/10.1016/S0304-405X(03)00174-0

Copeland, T. E. (1979). Liquidity Changes Following Stock Splits. Journal of Finance, 34, 115-141. http://dx.doi.org/10.1111/j.1540-6261.1979.tb02075.x

French, D. W., \& Foster III, T. W. (2002). Does Price Discreteness Affect the Increase in Return Volatility 
Following Stock Splits? Financial Review, 37(2), 281-293. http://dx.doi.org/10.1111/1540-6288.00015

Goldstein, M. A., \& Kavajecz, K. A. (2000). Eighths, sixteenths, and market depth: changes in tick size and liquidity provision on the NYSE. Journal of Financial Economics, 56, 125-149. http://dx.doi.org/10.1016/S0304-405X(99)00061-6

Grossman, S., \& Miller, M. H. (1988). Liquidity and Market Structure. Journal of Finance, 43, 617-633. http://dx.doi.org/10.1111/j.1540-6261.1988.tb04594.x

Hameed, A., \& Terry, E. (1998). The effect of tick size on price clustering and trading volume. Journal of Business Finance and Accounting, 25, 849-867. http://dx.doi.org/10.1111/1468-5957.00216

Harris, L. (1991). Stock Price Clustering and Discreteness. Review of Financial Studies, 4, 389-416. http://dx.doi.org/10.1093/rfs/4.3.389

Harris, L. (1994). Minimum Price Variations, Discrete Bid-Ask Spreads, and Quotation Sizes. Review of Financial Studies, 7, 149-178. http://dx.doi.org/10.1093/rfs/7.1.149

Harris, L. (1996). Does a Large Minimum Price Variation Encourage Order Exposure? Working Paper, University of Southern California.

Kadan, O. (2006). So Who Gains From a Small Tick Size? Journal of Financial Intermediation, 15, 32-66. http://dx.doi.org/10.1016/j.jfi.2004.09.003

Münnix, M. C., Schäfer, R., \& Guhr, T. (2010). Impact of the tick-size on financial returns and correlations. Physica A: Statistical Mechanics and its Applications, 389(21), 4828-484.

Onnela, J. P., Toyli, J., \& Kaski, K. (2009). Tick Size and Stock Returns. Physica: A Statistical Mechanics and its Applications, 388, 441-454. http://dx.doi.org/10.1016/j.physa.2008.10.014

Ronen, T., \& Weaver, D. G. (2001). Teenies 'Anyone? Journal of Financial Markets, 4(3), 231-260. http://dx.doi.org/10.1016/S1386-4181(00)00023-9

Schultz, P. (2000). Stock Splits, Tick Size and Sponsorship. Journal of Finance, 55, 429-450. http://dx.doi.org/10.1111/0022-1082.00211

Smith, B. F., Turnbull, D. A. S., \& White, R. W. (2006). The Impact of Pennies on the Market Quality of the $\begin{array}{llll}\text { Toronto Stock } & \text { Exchange. } & \text { Financial 273-288. }\end{array}$ http://dx.doi.org/10.1111/j.1540-6288.2006.00141.x

Van Ness, R., Van Ness, B., \& Pruitt, S. (2000). The Impact of the Reduction in Tick Increments in Major U.S. Markets on Spreads, Depth, and Volatility. Review of Quantitative Finance and Accounting, 15, 153-167. http://dx.doi.org/10.1023/A:1008369114062

\section{Copyrights}

Copyright for this article is retained by the author(s), with first publication rights granted to the journal.

This is an open-access article distributed under the terms and conditions of the Creative Commons Attribution license (http://creativecommons.org/licenses/by/3.0/). 